\title{
A SIMPLE TECHNIQUE FOR ARTHRODESIS OF THE ANKLE
}

\author{
CLEMENT C. BACIU \\ From the Colentina Clinical Hospital, Bucharest
}

\begin{abstract}
We report the results of a simple technique of ankle arthrodesis which is, however, indicated only when the foot can be reduced manually to a functional position. A special milling-cutter with an expulsion piston is used to obtain a cylindrical bone graft which is reintroduced having been reversed from left to right and rotated through 90 . The operation is simple and very rapid. It has been performed on 72 patients, 62 of whom have been followed up for an average of six years. Fifty-seven were painless with bony fusion in a functional position; one was solid and painless but in valgus. In only four patients were the results unsatisfactory.
\end{abstract}

The technique for ankle arthrodesis we describe can be used for painful osteoarthritis or for paralysis, but only when there is no fixed deformity and the foot can be placed in a functional position.

The use of an image intensifier and a milling-cutter with an expulsion piston, designed by the author and $\mathrm{E}$. Filibiu, has so simplified the operation that it takes only 8 to 10 minutes. The milling-cutter is a hollow cylinder $170 \mathrm{~mm}$ long with an 18-mm diameter (Fig. 1); at one end is a cutting edge and at the other a piston for expelling the bone graft (Fig. 2). The piston is cannulated to allow the passage of a Kirschner wire (Fig. 3).

\section{MATERIAL AND METHODS}

Since June 1973 we have operated on 72 ankles in 72 patients. The causes of deformity were post-traumatic osteoarthritis in 67 patients. poliomyelitis in two, cerebral palsy in one, post-traumatic peroneal nerve palsy in one and tabetic arthropathy in one. The average age at operation was 36 years (range 20 to 53 years). The right ankle was involved in 40 patients $(56 \%)$ and the left in 32 $(44 \%)$ (Table I).

Operation. With the patient supine and using an image intensifier, a Kirschner wire is introduced from the middle of the base of the medial malleolus through the joint space of the ankle to emerge through the lateral malleolus (Fig. 4, top). A vertical incision of 4 or $5 \mathrm{~cm}$ is made over the medial malleolus above and below the Kirschner wire, and the periosteum raised around the wire. The milling-cutter is threaded over the Kirschner wire and using a to-and-fro rotary movement, the cutter is progressively passed through the medial malleolus, the distal end of the tibia and proximal surface of the talus, the distal tibiofibular joint and finally the medial portion of the lateral malleolus, leaving its lateral cortex intact

C. C. Baciu. MD. Assistant Professor and Reader, Department of Orthopaedics

Colentina Clinical Hospital. Sos.Stefan cel Mare 21, Bucharest 72202. Rumania.

( 1986 British Editorial Society of Bone and Joint Surgery $0301620 \times 862037 \$ 2.00$

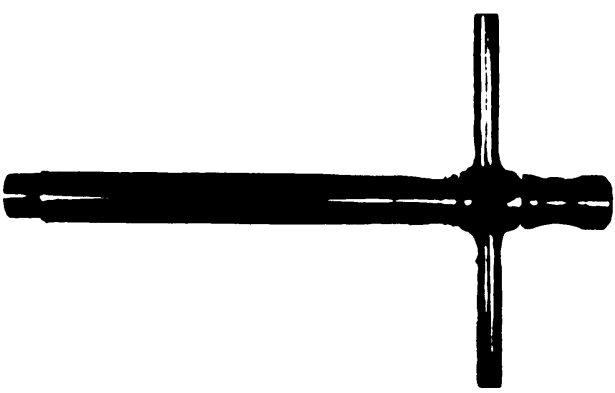

Fig. 1

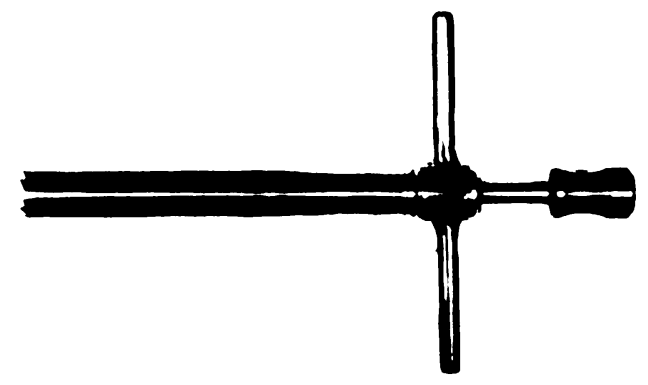

Fig. 2

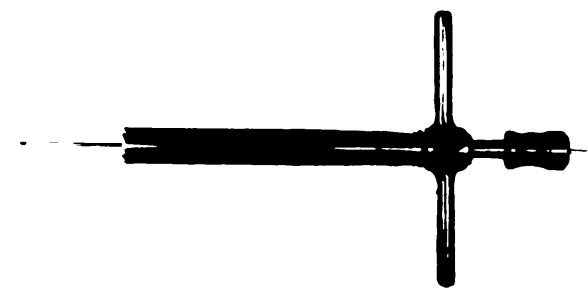

Fig. 3

The milling-cutter with the piston in the cylinder (Fig. 1); with the piston out (Fig. 2); and with the Kirschner wire threaded through the piston (Fig. 3).

(Fig. 4, middle). The wire is extracted laterally and the cutter with its contained bone graft medially. By means of a few hammer taps to the end of the piston, the cylindrical bone graft is expelled from the cutter. It is then reintroduced in reverse so that the medial end of the bone graft lies in the lateral malleolus; it is also rotated through 90 so that the original surface of the joint is now vertical (Fig. 4, bottom). 
Table I. Age, sex and affected ankle in 72 patients

\begin{tabular}{|c|c|c|c|c|c|}
\hline \multirow{2}{*}{$\begin{array}{l}\text { Age } \\
\text { (years) }\end{array}$} & \multirow{2}{*}{$\begin{array}{l}\text { Number of } \\
\text { patients }\end{array}$} & \multicolumn{2}{|l|}{ Sex } & \multicolumn{2}{|l|}{ Ankle } \\
\hline & & Male & Female & Right & Left \\
\hline $20 \quad 30$ & 14 & 6 & 8 & 9 & 5 \\
\hline 3140 & 32 & 13 & 19 & 18 & 14 \\
\hline $41-50$ & 21 & 9 & 12 & 11 & 10 \\
\hline 5153 & 5 & 2 & 3 & 2 & 3 \\
\hline Total & 72 & 30 & 42 & 40 & 32 \\
\hline
\end{tabular}

Table II. Period of follow-up of 62 patients

\begin{tabular}{ccccccccc}
\hline & \multicolumn{2}{c}{ Follow-up (years) } & & & & & \\
& 2 & 3 & 4 & 5 & 6 & 7 & 8 & 9 \\
\hline 62 & 6 & 8 & 7 & 10 & 9 & 9 & 7 & 6
\end{tabular}

After the operation the ankle is splinted in the desired final position; this depends upon the sex, profession and wishes of the patient. After removal of the sutures, a walking cast is applied and the patient walks with crutches, taking progressively more weight. After three weeks a stick alone is used. The walking cast is removed when clinical and radiological bony fusion of the ankle has been demonstrated, generally after three to four months.

\section{RESULTS}

Sixty-two of our patients who have had this type of ankle arthrodesis have been reviewed; 10 were operated on too recently to be included. The average length of follow-up was six years (Table II).

In 57 patients there was painless bony fusion in a good position (Figs 5 to 8 ). In one patient who had had a malunited bimalleolar fracture, union was in $10^{\circ}$ of valgus, but the result was still satisfactory.

In three patients with post-traumatic osteoarthritis bony fusion was not obtained, probably because of technical faults: in two of these the milling-cutter did not penetrate through the distal tibiofibular joint into the lateral malleolus; in the other the Kirschner wire was introduced only into the distal end of the tibia. The most

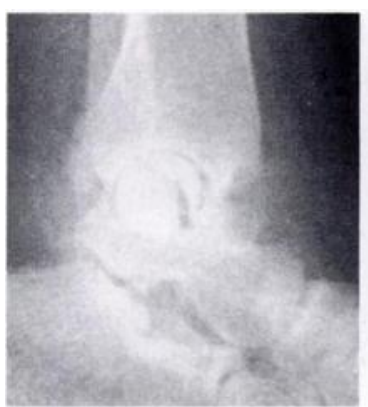

Fig. 5

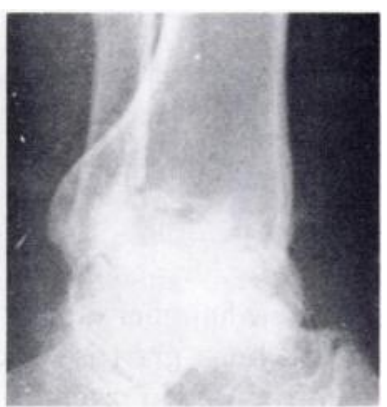

Fig. 6

Fig. 4

Operative technique: with the aid of an image intensifier, a Kirschner wire is introduced into the medial malleolus (top): the milling-cutter then progresses across the ankle joint into the lateral malleolus (middle): finally the bone graft is reintroduced after rotation in two planes (bottom).
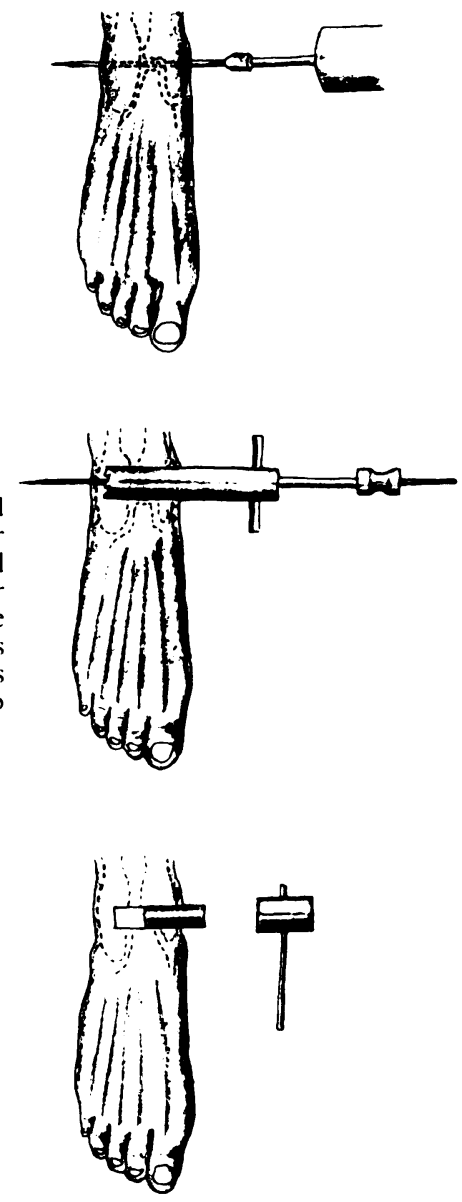

unsatisfactory result was obtained in the patient with tabetic arthropathy.

\section{DISCUSSION}

The present study included only patients with deformities of the ankle such that the foot could be manually reduced to a functional position. The advantages of our operative technique are its ease and speed (it can be completed in 8 to 10 minutes), the ability to take full weight soon after operation, and the relatively short period needed for bony fusion in a functional position. We found no significant increase of osteoarthritis in the other joints of the operated foot as compared with those of the contralateral foot.

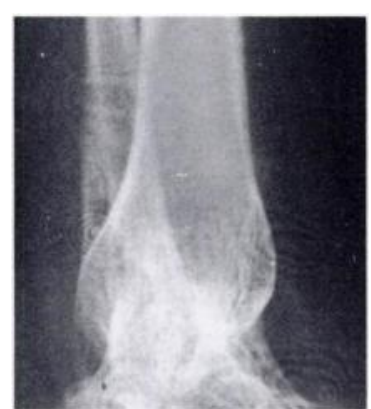

Fig. 7

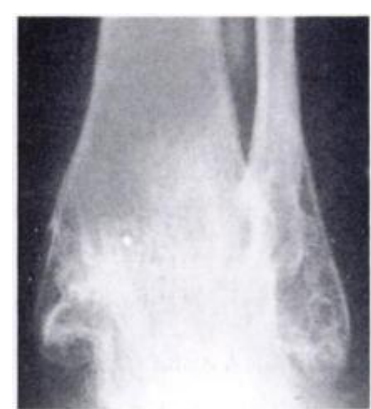

Fig. 8

Illustrative radiographs. Figure 5-Immediate postoperative film of a patient, showing the position of the bone graft. Figure 6-Lateral radiograph of another patient two years after operation. Figures 7 and $8-A$ third patient: radiographs eight years after operation show trabeculae crossing the ankle. 